https://doi.org/10.37208/tgn27206

\section{Chrysoclista linneella (Clerck, 1759) (Lepidoptera: Parametriotidae): a moth new to Scotland}

\author{
J.S.S. Charles ${ }^{1} \&$ E.G. Hancock ${ }^{2}$ \\ 1480 College St., Palmerston North 4410, New Zealand \\ ${ }^{2}$ The Hunterian (Kelvin Hall), University of Glasgow, \\ Glasgow G3 8AW \\ ${ }^{2}$ E-mail: geoff.hancock@ glasgow.ac.uk
}

During a visit to Callendar Park, Falkirk, Stirlingshire on 10th August 2019, in warm, sunny conditions, a small swarm of an unfamiliar and strikingly marked moth was seen by the first author near the trunk of a common lime tree (Tilia x europea L.) at NS897793. The swarm, close to the eastern side of the trunk at a height of around $2 \mathrm{~m}$, is estimated to have comprised a few dozen individuals. An example that alighted on the trunk was captured and was later identified as Chrysoclista linneella (Clerck, 1759), a species whose current known distribution in the British Isles extends only as far north as Ulverston, Cumbria (Dr Mark Young, pers. comm.).

This "micromoth" species is a member of the family Parametriotidae, although over the years it has moved through several re-classifications during which it has been positioned in a number of other families. It is one of a group of species that differ from related moths in being bark feeders or twig borers rather than exploiting leaves. $C$. linneella utilises one of the native European lime trees of which the common lime is prevalent in Callendar Park. From this behaviour it has been allocated a descriptive English vernacular name of linden bark borer in North America, where it was introduced into New York at some time prior to 1928 (BugGuide, 2019). In Britain two common names have been suggested. One is Linnaeus's spangle-wing, an approximate translation of its biological name: Chrysoclista means gold-washed in Greek (Emmet, 1991); and the other is lime cosmet. Neither of these is as descriptively useful as the American version.

To follow up this interesting discovery a visit was made by the second author on 23rd August 2019 and more examples were seen on a lime tree trunk (Fig. 1). There was a strong breeze and no adult moths were flying, but mating pairs and individuals were sitting exposed to view on the leeward side of the trunk (Fig. 2). Of seven lime trees examined two others showed signs of larval feeding in the form of reddish-brown frass (Fig. 3), but no adults were seen. It is possible the mini-populations on these trees were yet to emerge from their pupae or had already done so and had mated and died or dispersed.

This Scottish record is a considerable extension of the known U.K. distribution of $C$. linneella. The National Moth Recording Scheme local recorder for Stirlingshire, Dr Martin Culshaw, has been informed of this occurrence and Drs Keith Bland and Mark Young confirmed it as new to Scotland.

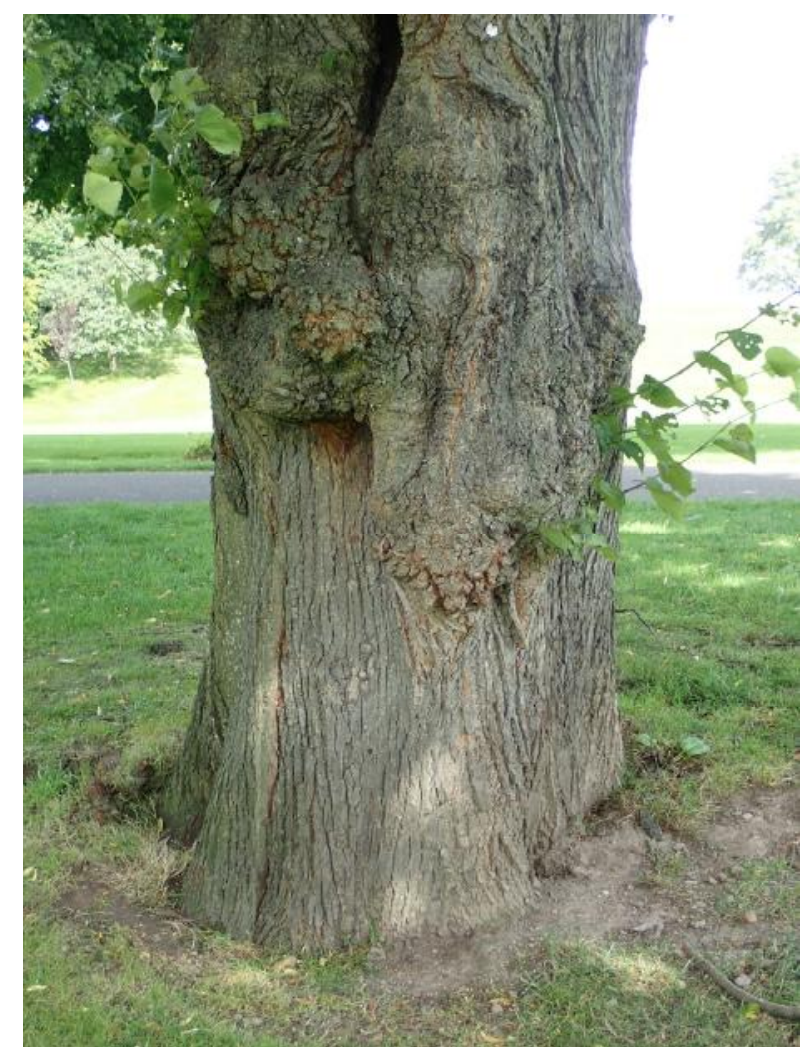

Fig. 1. Common lime (Tilia x europea) in Callendar Park, Falkirk, Scotland, 23rd August 2019, which was host to the moth Chrysoclista linneella. (Photo: E.G. Hancock)

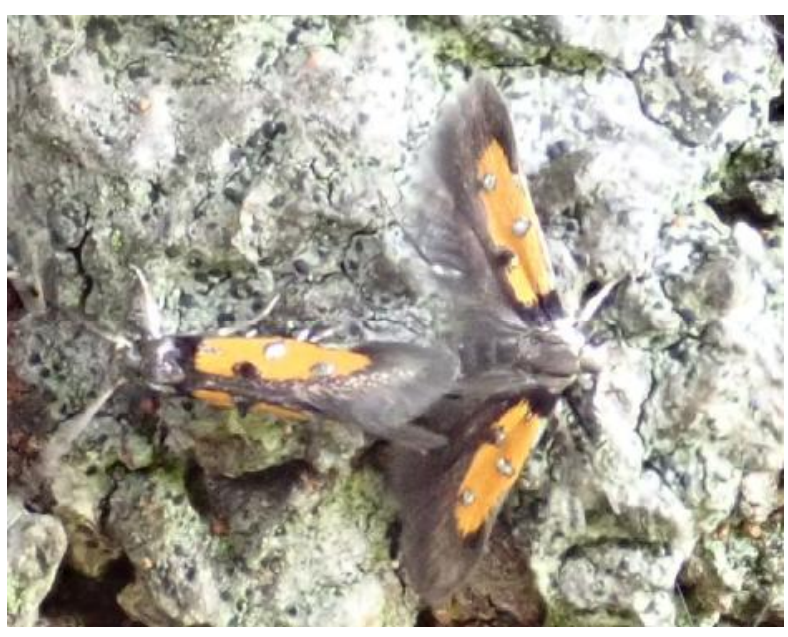

Fig. 2. A mating pair of Chrysoclista linneella on common lime (Tilia x europea) trunk, Callendar Park, Falkirk, 23rd August 2019. The wing length including apical fringe was $5.00 \mathrm{~mm}$. (Photo: E.G. Hancock) 


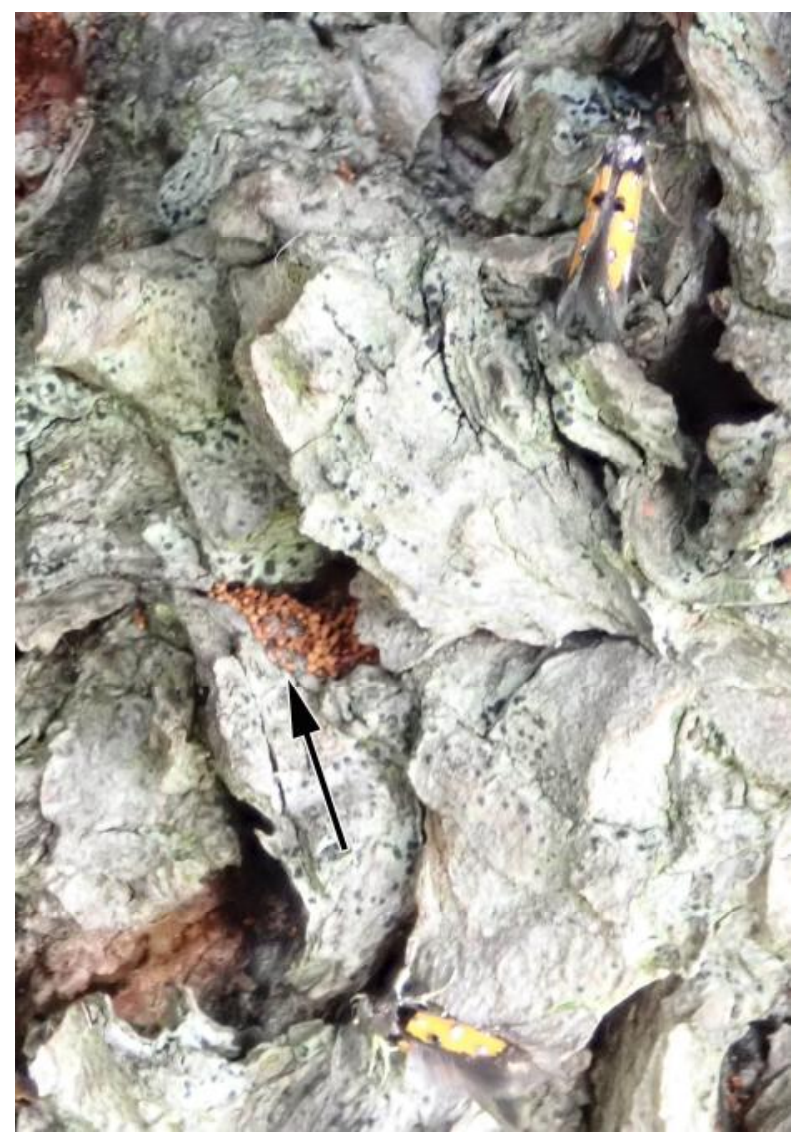

Fig. 3. Two adult Chrysoclista linneella with a patch of reddish-brown caterpillar droppings (frass) visible between two flakes of bark (arrow), Callendar Park, Falkirk, 23rd August 2019 (Photo: E.G. Hancock)

\section{REFERENCES}

BugGuide (2019).

https://bugguide.net/node/view/26402

Accessed 26th August 2019.

Emmet, A.M. (1991). The scientific names of the British Lepidoptera. Harley Books, Colchester. 